\title{
STUDI PEMANFAATAN KAYU PALA HUTAN (MyristicaFattua) BAGI MASYARAKAT KAMPUNG HAHA DISTRIK SEREMUK KABUPATEN SORONG SELATAN
}

\author{
IRNAWATI \\ irnawatif@gmail.com \\ DosenKehutananUniversitasMuhammadiyahSorong (UMS) \\ abstrak
}

Tujuan dari penelitian ini adalah untuk mengetahui pengetahuan masyarakat dalam memanfaatkan pala hutan dan berbagai bentuk pemanfaatan pala hutan oleh masyarakat Kampung Haha Distrik Seremuk Kabupaten Sorong Selatan.

Penelitian ini menggunakan metode deskriptif dengan teknik survey dan wawancara semi struktural (semi structural interview). Untuk wawancara, telah disiapkan topik-topik pertanyaan penentuan responen contoh dilakukan secara purposif sampling sebesar 20\% dari jumlah KK di Kampung Haha yang didasarkan atas pertimbangan masyarakat/petani yang sering memanfaatkan tanaman pala hutan dari hutan berdasarkan pengetahuan tradisional mereka. Teknik sampling menggunakan purposive sampling technique dengan jumlah sampel adalah 17 responden

Setelah melakukan analisis, maka kesimpulan studi adalah : Pemanfaatan kayu Pala Irian (MyristicaargenteaWarb.) oleh masyarakat di Kampung Haha Distrik Seremuk Kabupaten Sorong Selatan sebagaian besar dipergunakan untuk perkakas rumah tangga, kayu bakar (kayu energi), pembuatan perahu (kano) dan berbagai souvenir lainnya. Prospek pemanfaatan Pala Irian (MyristicaargenteaWarb.) kayunya cukup prospektif dan memberikan kontribusi pendapatan yang cukup baik sebagai sumber penghasilan masyarakat setempat. Persepsi pengetahuan masyarakat akan manfaa tkayu Pala Irian (MyristicaargenteaWarb.) oleh masyarakat setempat diperoleh secara turun-temurun dan selama ini belum ada upaya konservasi dari institusi local dan luar untuk melindungi spesies pala Irian ini.

Kata Kunci :PohonKayu Pala Hutan, Polapemanfaatan

\section{PENDAHULUAN}

\section{Latar Belakang}

Provinsi Papua Barat memiliki banyak kampung yang mempunyai keunikan flora tersendiri yang sangat menarik untuk diteliti, salah satunya Kampung Haha.Pemilihan lokasi ini sebagai lokasi eksplorasi dan penelitian dengan pertimbangan bahwa masyarakat di Kampung ini banyak memanfaatkan tumbuhan dan tanaman hutan dari hutan sebagai penyangga hidupnya.

Sebagai sumberdaya alam yang terbarukan, tumbuhan memiliki berbagai manfaat penting bagi keberlangsungan hidup manusia.Pengelolaan hutan yang baik harus dapat memberikan manfaat yang optimal bagi masyarakat, pengelola hutan dan stakholders serta lingkungan sekitarnya. Tidak hanya itu, pengelolaan hutan yang baik juga harus memperhatikan aspek-aspek kelestarian hutan, seperti : aspek ekologi, produksi, serta sosial ekonomi dan budaya masyarakat sekitar hutan (Purnawan, 2006). Adanya masyarakat yang tinggal di sekitar hutan yang mempunyai akses langsung maupun tidak langsung 
terhadap kawasan hutan serta memanfaatkan sumberdaya hutan adalah suatu realita yang tidak bisa diabaikan. Kondisi ini tentunya akan berdampak positif maupun negatif terhadap kelestarian hutan. Kegagalan pengelolaan hutan yang terjadi selama ini bukan disebabkan oleh faktor teknis semata namun lebih disebabkan oleh faktor sosial. Oleh karena itu, pengelolaan hutan yang baik tidak hanya memperhatikan aspek teknis pengelolaan hutan, namun juga harus memperhatikan aspek sosial (Nurrochmat, 2005).

Kehidupan masyarakat desa sekitar hutan tidak bisa dipisahkan dari keberadaan hutan tempat mereka menggantungkan hidupnya.Tingginya angka kemiskinan dan laju pertumbuhan penduduk yang terus meningkat dari tahun ke tahun menjadi permasalahan besar dalam pembangunan hutan.Tekanan terhadap hutan terus meningkat serta tuntutan terhadap pemenuhan kebutuhan hidup dan penyediaan lahan untuk areal pemukiman dan fungsi-fungsi lainnya menjadi lebih besar. Implementasi kegagalan pengelolaan hutan akan berdampak pada meningkatnya deforestasi hutan. Paradigma hutan dalam pengelolaan dan pembangunan hutan yang melibatkan masyarakat merupakan harapan baru untuk dapat memecahkan permasalahan yang terjadi dalam pembangunan kehutanan (Darusman, 1992) tingkat ketergantungan masyarakat terhadap keberadaan sumberdaya hutan sangat tinggi, namun sejauh ini belum diketahui secara pasti jenis dan besaran nilai manfaat yang diperoleh masyarakat dari hasil pemanfaatan sumberdaya hutan tersebut.

Salah satu jenis hasil hutan non kayu yang banyak terdapat di Indonesia adalah tanaman obat.Tanamn obat di Indonesia banyak ragamnya, mulai dari penggunaan akar atau rimpang, batang, kulit kayu, daun, buanga, buah, biji, kulit buah, dll. Dalam proposal ini, contoh tanaman obat yang merupakan salah satu hasil hutan non kayu adalah pala (Myristica fragrans ). Pala (Myristica fragransHoutt) merupakan salah satu komoditi pertanian yang memiliki nilai ekonomis tinggi, di samping berjenis-jenis komoditi pertanian ekonomis lainnya.

Kegunaan pala sebagai hasil hutan yang bernilai ekonomis, ternyata tanaman ini digunakan juga oleh masyarakat kampung Haha sebagi bahan pembuat obat serta penggunaan lainnya oleh masyarakat setempat contohnya akar atau rimpang, batang, kulit kayu, daun, bunga, buah, biji, kulit buah, yang mereka gunakan dalam pemanfaatan kehidupan masyarakat setempat. Pala hutan tersebut dapat diperoleh di sekitar kampungHaha menyebar dengan sendirinyasecara alami.

Pemanfaatan pala hutan merupakan pengetahuan lokal yang dimiliki oleh masyarakat setempat yang perlu dikaji. Pengetahuan lokal ini akan menjadi pengetahuan umum jika dokumentasi tertulis dan dipublikasikan secara umum, terutama dalam usaha untuk mencari alternatif lain penggunaan jenis-jenis kayu baru yang ada di lokasi setempat sebagai bahan baku perbagai keperluan hidup manusia. Tanaman berperan penting dalam kehidupan manusia.Pemanfaatan tumbuhan merupakan sumber bahan 
pangan, papan, sandang, obat, kerajinan, keiatan sosial dan sebagainya. Purwanto, dkk (2003) mengemukakan bahwa terdapat 3 kelompok pengguna produk hasil hutan non kayu yaitu : a) masyarakat lokal b) konsumen urban dan c) perusahaan.

$$
\text { Masyarakat Kampung Haha }
$$

Distrik Seremuk Kabupaten Sorong Selatan merupakan salah satu contoh masyarakat/suku yang senantiasa melakukan interaksi dengan alam lingkungan sekitarnya.Ini terlihat dalam pemenuhan kebutuhan hidup dalam membuat ramuan obat, mereka memanfaatkan pala hutan yang terdapat dilingkungan tempat tinggalnya.

Pola pemanfaatan pala hutan bagi kehidupan masyarakat kampung Haha tersebut sangatlah penting untuk dikaji melalui penelitian ini. Masyarakat juga memandang bahwa hutan sebagai sesuatu yang telah tersedia untuk dapat digunakan dalam kehidupan sehari-hari untuk memperhatikan penggunaan sumber daya hutan dalam jumlah yang besar akan berpengaruh nyata terhadap ekosistem hutan. Informasi tentang pengetahuan dan pemanfaatan pala hutan oleh masyarakat di Kampung Haha Distrik Seremuk Kabupaten Sorong Selatan belum banyak diketahui, oleh sebab itu dirasakan perlu untuk mengetahui bagaimana pemanfaatan pala hutan oleh masyarakat bagi kehidupan mereka.

\section{Rumusan Masalah}

Dari latar belakang diatas, dapat dirumuskan ada 2 (dua) permasalahan dalam penelitian ini antara lain :

1. Bagaimana pengetahuan masyarakat dalam memanfaatkan pala hutan di
Kampung Haha Distrik Seremuk Kabupaten Sorong Selatan?

2. Bagaimana bentuk pemanfaatan pala hutan oleh masyarakat Kampung Haha Distrik Seremuk Kabupaten Sorong Selatan?

\section{Tujuan Penelitian}

Adapun tujuan penelitian ini adalah sebagai berikut :

1. Untuk mengetahui pengetahuan masyarakat dalam memanfaatkan pala hutan di Kampung Haha Distrik Seremuk Kabupaten Sorong Selatan.

2. Untuk mengetahui berbagai bentuk pemanfaatan pala hutan oleh masyarakat Kampung Haha Distrik Seremuk Kabupaten Sorong Selatan.

\section{METODOLOGI PENELITIAN Lokasi dan Waktu Penelitian}

Penelitian akan dilakukan di Kampung Haha Distrik Seremuk Kabupaten Sorong Selatan. Waktu penelitian ini direncanakan ( \pm 2 bulan) dari bulan Juli sampai Agustus 2014.

\begin{abstract}
Alat dan Bahan
Alat yang digunakan dalam penelitian ini antara lain kamera photo/digital dan alat tulis menulis. Bahan yang menjadi objek penelitian ini adalah berbagai jenis tanaman pala hutan yang dimanfaatkan berdasarkan pengetahuan lokal oleh masyarakat Kampung Haha Distrik Seremuk Kabupaten Sorong Selatan.
\end{abstract}

\section{Metode Penelitian}

Metode yang digunakan dalam penelitin ini adalah metode deskriptif dengan teknik survey dan wawancara semi struktural (semi structural 
interview). Untuk wawancara telah disiapkan topik-topik pertanyaan penentuan responen contoh dilakukan secara purposif sampling sebesar $20 \%$ dari jumlah KK di Kampung Haha yang didasarkan atas pertimbangan masyarakat/petani yang sering memanfaatkan tanaman pala hutan dari hutan berdasarkan pengetahuan tradisional mereka.

Data yang dikumpulkan dalam penelitian ini meliputi data primer dan sekunder dimana,data Primer diperoleh dan wawancara terhadap masyarakat yang memanfaatkan tumbuhan secara tradisional dengan berpedoman pada kusioner yang telah disiapkan. Pemanfaatan tanaman pala hutan oleh penduduk setempat, data yang dikumpulkan meliputi informasi etnobotani yang menyangkut bentuk pemanfaatan jenispala hutan, bagian tumbuhan yang digunakan dari cara pemanfaatan. Bentuk pendekatan yang digunakan untuk mengklasifikasikan bentuk-bentuk pemanfaatan menggunakan klasifikasi Alhamid dan Kuswandi (1998) yang mengelompokkan kedalam 8 kelompok berdasarkan tujuan pemanfaatannya yakni (a).Makanan, (b).Minuman, (c).Bahan konstruksi, (d).Kayu perkakas, (e).Obat, (f).Magis, (g).Seni, dan (h).bahan bakar. Data sekunder diperoleh dari instansi-instansi yang terkait dan penelitian yang relevan dengan penelitian ini.

\section{Variabel Penelitian}

Variabel dalam penelitian ini meliputi :

1. Pengetahuan lokal (local knouwledge) masyarakat dalam memanfaatkan pala hutan bagi kehidupan masyarakat kampung Haha.

2. Jenis dan bentuk pemanfaatan Pala hutan oleh masyarakat.

\section{Prosedur \& Teknik Pengambilan Data}

Prosedur penelitian yang akan digunakan dalam penelitian ini adalah :

1. Survei lapangan untuk mengetahui sosial ekonomi masyarakat yang memanfaatkan pala hutan berdasarkan pengetahuan lokal (local knowledge) mereka.

2. Observasi secara langsung terhadap masyarakat yang pemanfaatan pala hutan berdasarkan pengetahuan lokal (local knowledge) mereka.

3. Mewawancarai secara langsung dan bebas dengan masyarakat yang memanfaatkan pala hutan.

4. Mengumpulkan data primer dan sekunder

a. Data primer meliputi jenis pala hutan dan pemanfaatannya oleh masyarakat setempat.

b. Data sekunder meliputi keadaan umum lokasi penelitian dan sosial ekonomi masyarakat setempat.

5. Organisasi dan kompilasi data

6. Analisis data

\section{Analisis Data}

Data yang dukumpulkan diolah secara labulasi sederhana serta dianalisis secara deskriptif kualitatif berdasarkan jenis pala hutan dan pemanfaatannya oleh masyarakat serta disajikan dalam bentuk gambar.Teknik pengumpulan data yang dilakukan dalam penelitian ini secara lengkap dapat dilihat pada Gambar dibawah ini. 


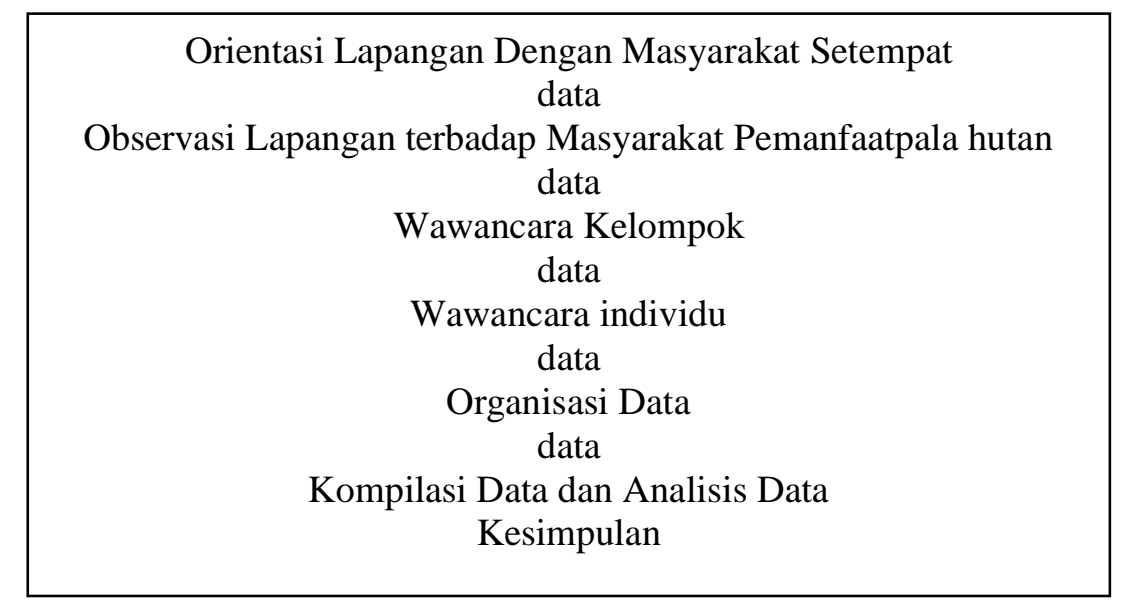

\section{HASIL DAN PEMBAHASAN}

\section{A. Keadaan Umum Areal Penelitian}

\section{Letak Desa/Kampung}

Kampung Haha secara administratif termasuk dalam wilayah Distrik Seremuk Kabupaten Sorong Selatan dengan luas wilayah $250 \mathrm{~m}^{2}$ dengan batas-batas wilayah adalah sebagai berikut :

a. Sebelah Utara berbatasan dengan Distrik Teminabuan

b. Sebelah Selatan berbatasan dengan Distrik Aitinyo

c. Sebelah Timur berbatasan dengan Distrik Kais

d. Sebelah Barat berbatasan dengan Distrik Wayer

\section{Tofografi dan Tanah}

Keadaan tofografi Kampung Haha bervariasi dari datar, berbukit-bukit dan lautan.Jenis tanah adalah aluvial, tanah ini merupakan jenis tanah yang bersal dari endapan gunung dengan tekstur tanah liat hingga berpasir yang berwarna hitam kecoklatan dan berhumus.

\section{Flora dan Fauna}

Jenis-jenis flora yang tumbuh dihutan secara alami adalah matoa (Pometia spp), kayu Besi (Instia spp), Ketapang (Terminalla catappa), Beringin (Ficus spp), Bakau
(Rhizophora spp, Bruguiera spp).dan Damar (Agathis labillardieri) sedangkan flora yang dikembangbiakkan antara lain Mangga (Mangifera indica), Sukun (Artocarpus altilis), Durian (Durio zibethinus), Pisang (Musa paradisiaca) dan Nangka (Artocarpus integra).

Jenis-jenis fauna yang hidup secara liar di alam adalah Cendrawasih (Paradisea spp), Kus-kus (Phallanger), Babi hutan (Sus papuensis), Tikus tanah (Echymiphera sp), dan Kasuari (Casuarius casuarlus).

\section{Hidrologi}

Sumber air bagi masyarakat desa berasal dari sungai Sisyah dan sungai Waren, sedangkan yang keluar dari mata air adalah mata air Sewon. Sumber air ini yang dimanfaatkan masyarakat untuk keperluan dapur/masak, mandi dan mencuci.

\section{Penduduk}

Penduduk Kampung Haha berjumlah 441 jiwa yang terdiri dari 206 jiwa laki-laki dan 235 jiwa perempuan dengan jumlah kepala keluarga sebanyak $123 \mathrm{KK}$. Tingkat pendidikan masyarakat rata-rata masih sangat rendah, yakni dari jumlah KK tersebut, $56 \mathrm{KK}(45,53 \%)$ termasuk kategori rendah. Kondisi ini mengakibatkan 
akses masyarakat dalam pemanfaatan kayu pala masing sangat tinggi. (Sumber daya : Kantor Distrik Seremuk, 2014).

\section{a. Usaha Tani}

Sistim pertanian yang diterapkan oleh masyarakat adalah sistem pertanian tradisional yaitu dengan cara menebang, membakar dan menanam, sedangkan untuk usaha nelayan pada umumnya dilakukan oleh laki-laki dan hasilnya untuk kebutuhan keluarga dan sebagian dijual.

Jenis-jenis komoditi pertanian serta produksi dan produktifitas menurut komoditi bidang pertanian yang diusahakan masyarakat di Kampung Haha Distrik Seremuk Kabupaten Sorong Selatan seperti pada pada tabel berikut

ini.

Tabel 3. Data Jenis Cabang Usahatani, Luas Lahan, produksi, dan produktifitas di Kampung Haha Tahun 2014

\begin{tabular}{clccc}
\hline No & Jenis Bidang Pertanian & $\begin{array}{c}\text { Luas Tanam } \\
\left(\mathbf{m}^{\mathbf{2}}\right)\end{array}$ & $\begin{array}{c}\text { Produksi } \\
(\mathbf{k g})\end{array}$ & $\begin{array}{c}\text { Produktifitas } \\
(\mathbf{K g} / \mathbf{H a})\end{array}$ \\
\hline 1 & Ubi-ubian & 1.500 & $1.319,18$ & $8.794,53$ \\
2 & Sayuran & 1.500 & 457,27 & $3.048,47$ \\
3 & Karbohidrat Non Ubi-ubian & 1.500 & 355,06 & $3.550,60$ \\
4 & Hasil Hutan Pala & 7.000 & $1.383,75$ & $1.976,79$ \\
\hline
\end{tabular}

Dari semua bidang usaha pertanian di kampung Haha, terlihat bahwa hasil hutan pala merupakan komoditi dengan luas paling besar namun memiliki produktifitas paling kecil.Hal ini disebabkan karena hutan pala sangat jauh dari pemukiman dan waktu panen yang cukup lama sebaliknya karbohidrat non ubi-ubian memiliki luas daerah yang kecil tetapi memiliki produktifitas yang besar.

\section{b. Potensi Sumber Daya Alam}

Kelayakan suatu wilayah untuk dijadikan kawasan sentra produksi kayu pala ditentukan oleh beberapa hal.Keputusan menetapkan kawasan tertentu menjadi sentra produksi kayu pala didasarkan pada hasil studi kelayakan kawasan tersebut.Studi dilakukan terhadap potensi sumber daya lahan, hidrologi, aksesbilitas transportasi.Aspek lingkungan dan rentang pusat pemasaran hasil hutan kayu pala Irian.

Pemanfaatan potensi sumber daya alam di Kampung Haha guna pemberdayaan ekonomi masyarakat setempat sangat prospektif.Hal ini terkait kelayakan berbagai aspek yang memungkinkan kawasan tersebut dijadikan sebagai daerah sentra produksi hasil hutan pala.

\section{c. Kebudayaan}

Kebudayaan masyarakat kampung Haha umumnya masih mengikat, dimana dipengaruhi oleh adat istiadat. Keadaan ini dapat dilihat pada berbagai kegiatan seperti acara perkawinan, penyelesaian perselisihan antar warga, perceraian, pemilikan dan penggunaan hak ulayat tanah adat dan dusun sagu serta perkara lain yang selalu diselesaikan secara adat oleh para tetua adat, tokoh agama dan tokoh masyarakat.

\section{Ciri dan Karakteristik Kayu Pala Irian (Myristica argentea Warb.)}

Berdasarkan hasil survey dan identifikasi serta wawancara dengan masyarakat Kampung $\mathrm{HaHa}$ Seremuk Kabupaten Sorong Selatan, maka deskripsi jenisPala Irian (Myristica argentea Warb.) berdasarkan ciri dan karakteristrik adalah sebagai berikut :

a. Perawakan dan habitat : pohon berbatang tunggal, tumbuh tunggal dengan tinggi mencapai $25 \mathrm{~m}$, tumbuh pada tanah basah 


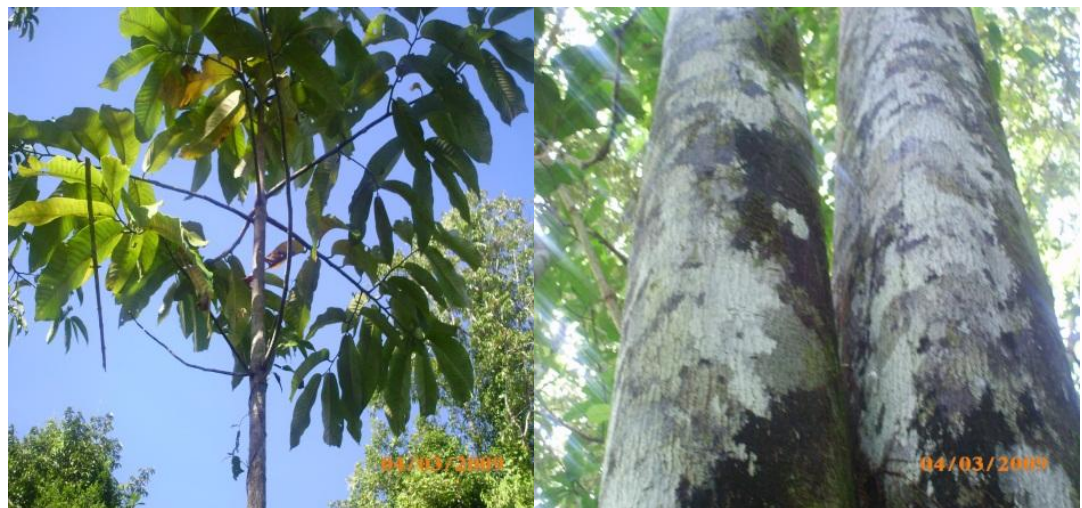

Gambar 2.Bentuk Pohon Pala Irian (Myristica argentea Warb.)

b. Batang : Bentuk pohon pala Irian (Gambar 2 dan gambar 3) berpenampilan indah, tinggi dapat mencapai $25 \mathrm{~m}$, menjulang tinggi ke atas dan ke pinggir, lonjong (silindris) dan bulat dengan percabangan relatif teratur, diameter dapat mencapai $40 \mathrm{~cm}$, bentuk batang silindris dan tumbuh tegak, tekstur permukaan kasar, berwarna hitam cokelat keputih-putihan. Berdasarkan informasi dari para petani pala di areal penelitian, penentuan pohon pala jantan dan betina secara dini dapat diduga dari sudut percabangan. Percabangan mendatar diduga pohon betina dan sudut percabangannya meruncing diduga pohon jantan

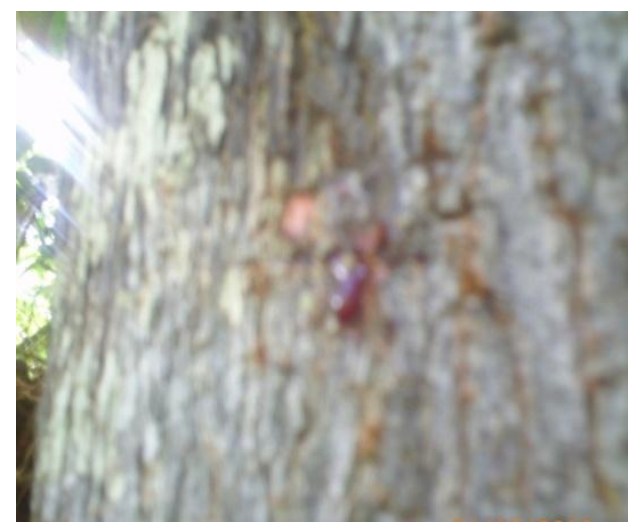

Gambar 3. Batang Pohon Pala Irian (Myristica argentea Warb.) c. Daun : Daunnya berwarna hijau dengan bintik-bintik kuning, panjang $10-15 \mathrm{~cm}$ dengan lebar $5-10 \mathrm{~cm}$, panjang tangkai daun dapat mencapai5 cm; berbentuk bulat memanjang, permukaan daun kasar dan mengkilat saat muda dan tepi daun bergelombang (gambar 4. ), ujung daun lancip. Penentuan jenis kelamin secara dini dapat diduga dari bentuk helaian daun. Bentuk helaian daun lebih terkulai merupakan ciri pala betina. Sedangkan bentuk helaian daun yang relatif lebih kecil dengan letak daun lebih tegak, menunjukan pala jantan.

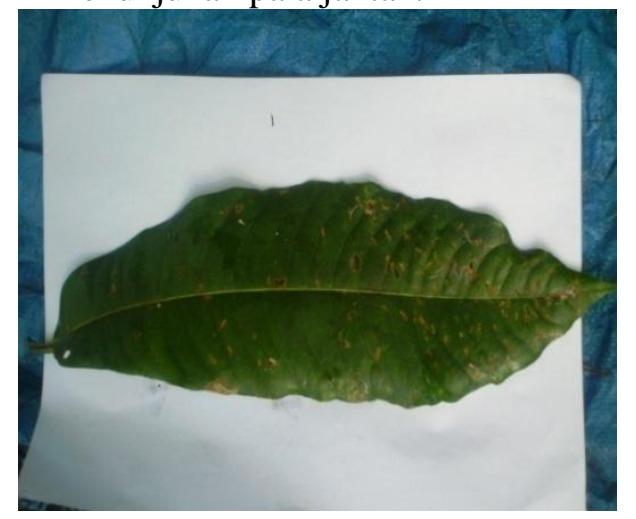

Gambar 4. Daun Pala (Myristica argentea Warb.)

d. Bunga : Bunga keluar dari ujung cabang dan ranting. Bunga betina mempunyai kelopak dan mahkota meskipun perkembangannya tidak sempurna. Warna bunga kuning 
keputih-putihan, dengan diameter \pm $2,5 \mathrm{~mm}$ serta panjangnya $\pm 3 \mathrm{~mm}$.di bawah dedaunan, panjang hingga 60 $\mathrm{cm}$. Mahkota bunga betina bersatu mulai dari bagian pangkal dan pada bagian atas terbuka menjadi 2 bagian yang sistematis. Kelopak kecil dan menutup sebagian kecil dari bagian bawah mahkota. Di dalam mahkota terdapat pistil yang bersatu dengan bakal bunga. Kepala putik terbelah pada bagian ujungnya. Di dalam bakal buah terdapat bakal kulit biji dan bakal biji. Bentuk bunga jantan agak berbeda dengan bunga betina walaupun warna bunganya juga kuning, dengan diameter 1,5 mm dan panjang $\pm 3 \mathrm{~mm}$. Mahkota dari bunga jantan bersatu dari pangkal pada 5/8 bagian dan kemudian terbagi menjadi 3 bagian. Kelopak berkembang tidak sempurna, bentuknya seperti cincin yang melingkar pada bagian pangkal mahkota. Benang sari berbentuk silindris merupakan tangkai bersatu, panjangnya $\pm 2 \mathrm{~mm}$. Sari melekat pada tangkai tersebut membentuk baris-baris yang jumlahnya 8 buah dan berpasangan. Antara baris dibatasi oleh jalur kecil $\pm 1 / 10 \mathrm{~mm}$ lebarnya.

e. Buah : bentuk buah bulat memanjang (Gambar 5.), ukuran diameter buah dapat mencapai $5 \mathrm{~cm}$ dengan permukaan kasar, warna hijau muda saat muda dan kuning saat matang, buah saat tua terbelah sehingga terlihat biji. Daging buah berwarna putih, tebal dapat mencapai $1 \mathrm{~cm}$.

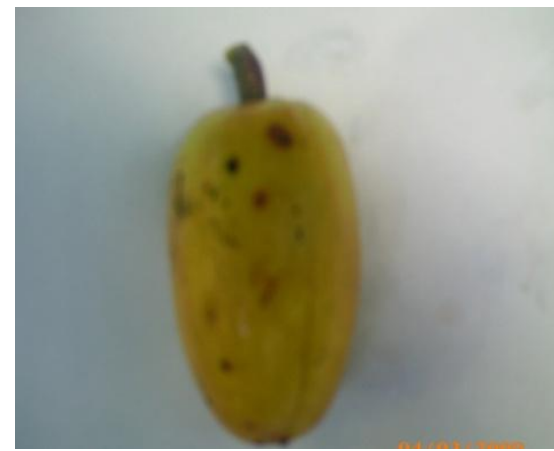

Gambar 5. Buah pala Irian

f. Biji :Buahnya bulat sampai lonjong, berwarna hijau kekuning-kuningan, apabila masak akan berbelah dua, diameter 3-6 cm. Daging buahnya/ pericarp tebal dan rasanya asam. Biji berbentuk bulat sampai lonjong, panjangnya $1,5-4,5 \mathrm{~cm}$ dengan lebar 1 - 2,5 cm. Warnanya kuning dan mengkilap pada bagian luarnya. Kernel bijinya berwarna keputihputihan. Fulinya merah gelap dan ada pula yang putih kekuning-kuningan dan membungkus biji menyerupai jala (Gambar 6). Petani pala di areal penelitian biasanya menentukan pala jantan atau betina dari bentuk bijinya. Biji yang memiliki permukaan ujung membukit diduga jantan dan biji yang bagian ujungnya rata diduga betina

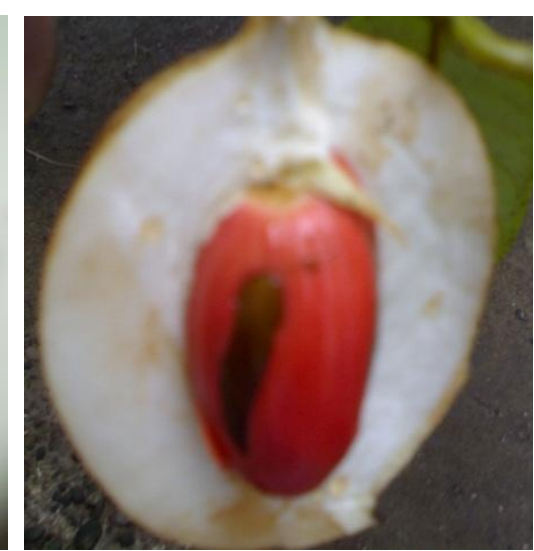

Gambar 6. Biji dan daging buah pala 


\section{Pola Pemanfaatan Kayu Pala Irian (Myristica argentea Warb.)}

Berdasarkan hasil penelitian menunjukan bahwa Pala Irian (Myristica argentea Warb.)dapar dimanfaatkan sebagai bahan kontruksi bangunan masyarakat setempat, seperti perkakas rumah tangga, pembuatan perahu (kano), dan berfungsi sebagai sumber kayu bakar (kayu energi) yang cukup potensial dan penghasil biji dan fuli yang bernilai ekonomis bagi peningkatan ekonomi rumah tangga masyarakat. Berikut bagian-bagian dari kayu Pala Irian yang mempunyai nilai manfaat bagi masyarakat di areal penelitian, antara lain:

a. Batang

Kampung Haha Distrik Seremuk Kabupaten Sorong Selatan merupakan salah satu kampung yang masyarakatnya memanfaatkan kayu pala Irian sebagai material dalam pembangunan rumah mereka. Menurut masyarakat responden, bahwa tidak semua perkakas/material konstruksi bangunan rumah mereka sebagian terbuat dari kayu pala Irian (Gambar 7).

Berdasarkan hasil penelitian dan wawancara dengan masyarakat responden di Kampung Haha Distrik Seremuk Kabupaten Sorong Selatan menunjukkan bahwa pemanfaatan batang kayu Pala Irian (Myristica argentea Warb.) lebih bernilai ekonomis dan prosfektif, hal dapat ditunjukan bahwa antara lain untuk kayu gergajian, papan, dan perkakas lain serta lebih unik lagi untuk dijadikan sebagai perahu (kano). Eksploitasi pemanfaatan kayu Pala Irian (Myristica argentea Warb.) di areal hutan Kampung Haha Distrik Seremuk Kabupaten Sorong Selatan dulu dilakukan oleh salah satu perusahaan kayu PT. Hasrat Wira Mandiri.

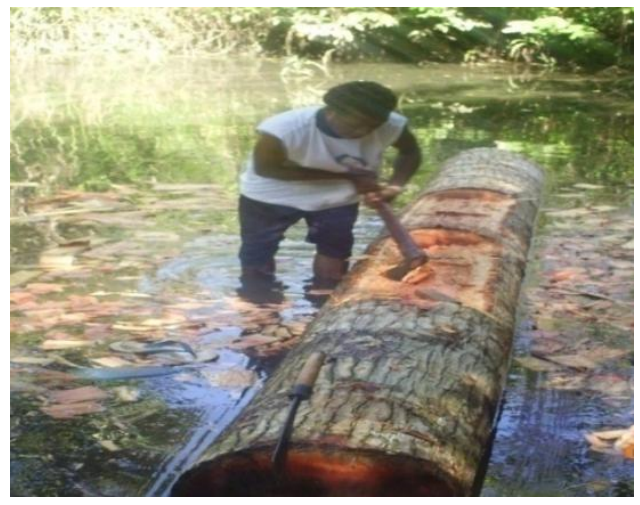

Gambar 7.Pembuatan perahu dari kayu Pala Irian (Myristica argentea Warb.)

Menurut informasi yang diperoleh dari masyarakat responden diketahui bahwa peralatan rumah tangga yang digunakan oleh masyarakat Kampung Haha ada sebagian yang berasal dari jenis kayu Pala Irian (Myristica argentea Warb.)misalnya badan perahu, meja, dan kursi. Kayu Pala Irian yang diambil untuk digunakan membuat peralatan tersebut adalah yang telah mencapai tinkat pohon yaitu yang berdiameter diatas $30 \mathrm{~cm}$.

Menurut masyarakat kampung Haha alasan mereka menggunakan jenis kayu tersebut adalah karena kayunya lentur sehingga mudah untuk dibentuk.Alasan yang diberikan sesuai dengan kebiasan secara turun-temurun dari masyarakat setempat bahwa untuk membuat badan perahu dayung dapat juga menggunakan jenis kayu pala Irian.

b. Kulit batang dan ranting

Pemanfaatan kulit batang dan ranting kayu pohon Pala Irian (Myristica argentea Warb.) yang sebagai kayu bakar (kayu energi).Fuli, Fuli adalah benda untuk menyelimuti biji buah pala (Gambar 8) yang berbentuk seperti anyaman pala, disebut "bunga pala". Bunga pala ini dalam bentuk kering dapat dijual. 


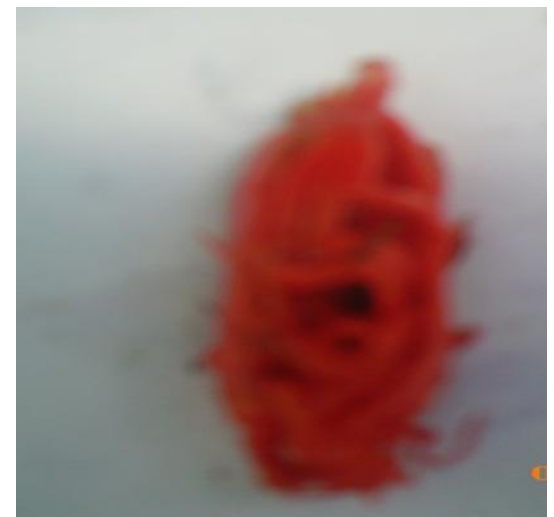

\section{c. Biji pala}

Biji pala dimanfaatkan oleh masyarakat kampung haha tidak bernilai ekonomis. Buah Pala Irian (Myristica argentea Warb.) sesungguhnya dapat meringankan semua rasa sakit dan rasa nyeri yang disebabkan oleh kedinginan dan masuk angin dalam lambung dan usus. Biji pala sangat baik untuk obat pencernaan yang terganggu, obat muntah-muntah dan lain-lainya.

Gambar 8. Fuli Pala Irian (Myristica argentea Warb.)

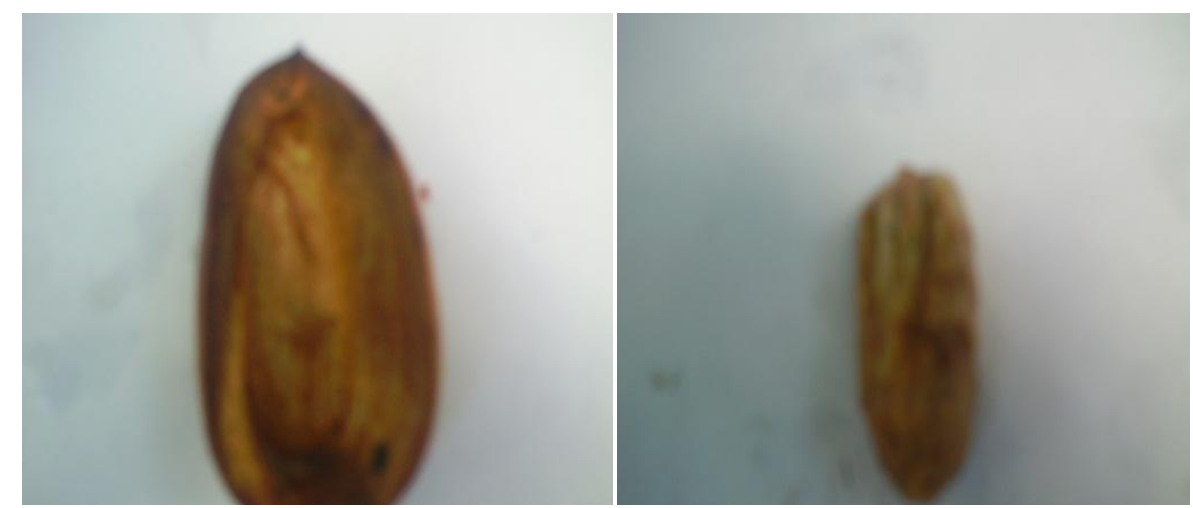

Gambar 9. Biji Pala Irian (Myristica argentea Warb.)

d. Daging buah Pala Irian (Myristica argentea Warb.)

Daging buah pala (Gambar 10) dapat dimanfaatkan oleh masyarakat jika menjadi makanan ringan seperti asinan pala atau manisan pala

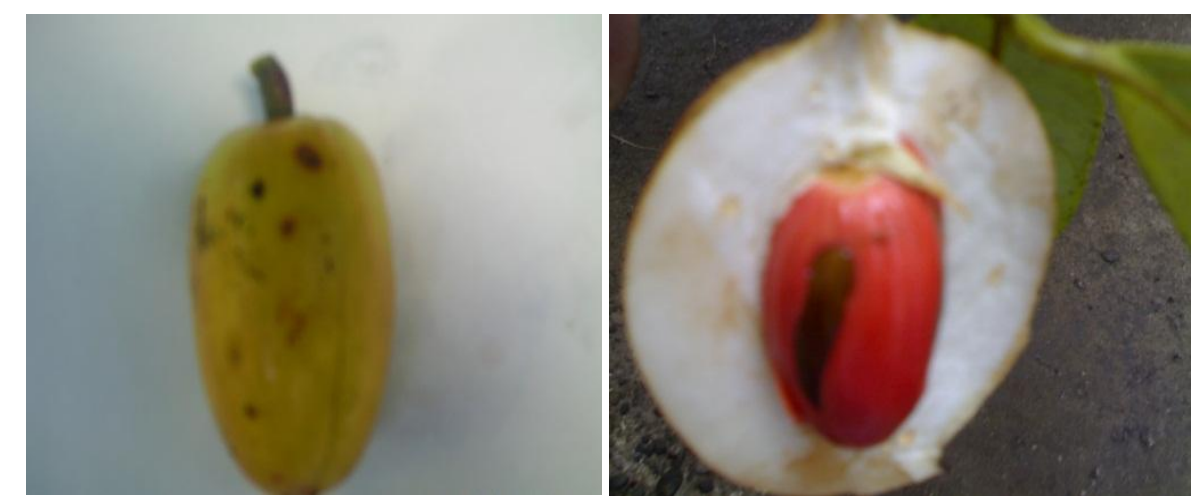

Gambar 10 Buah dan Daging Pala Irian (Myristica argentea Warb.)

e. Pemasaran Kayu Pala Irian (Myristica argentea Warb.)

Masyarakat di Kampung Haha produk asal kayu Pala Irian. Untuk kayu Distrik Seremuk Kabupaten Sorong Pala Irian ini biasanya masyarakat Selatan sering memasarkan produk- memotong atau mengambilnya di hutan 
untuk dimanfaatkan sendiri dan dijual. Biasanya untuk penjualan kayu jenis ini jarang dilakukan di pasar tetapi di lakukan dirumah, apabila Masyarakat yang memesan kayu mereka dapat membelinya langsung di rumah.

Penjualan kayu pala Irian oleh masyarakat umunya di jual per kubik, untuk 1 meter kubik harganya biasanya mencapai Rp. 750.000,0. Biasanya untuk kayu yang dipesan dijual dalam bentuk kayu balak. Jenis souvenir dari kayu Pala Irian ini juga kadang juga dipamerkan dalam kegiatan pameran baik di tingkat Distrik maupun di tingkat kabupaten.

\section{Persepsi Masyarakat Kampung Haha Tentang Pemanfaatan Kayu Pala Irian (Myristica argentea Warb.)}

Persepsi masyarakat tentang pemanfaatan kayu Pala Irian (Myristica argentea Warb.) di kampung Haha Distrik Seremuk Kabupaten Sorong Selatan disajikan pada tabel 4. dan penjelasan sebagai berikut :

Tabel 4. Distribusi persepsi msyarakat tentang pemanfaatan kayu Pala Irian (Myristica argentea Warb.) di kampung Haha Distrik Seremuk Kabupaten Sorong Selatan tahun 2009

\begin{tabular}{llcccc}
\hline \multirow{2}{*}{ No. } & \multicolumn{1}{c}{ Uraian } & \multicolumn{3}{c}{ Jumlah Masyarakat } & \multirow{3}{*}{$\sum$} \\
\cline { 3 - 5 } & & $\mathrm{A}$ & $\mathrm{B}$ & $\mathrm{C}$ & \\
\hline 1. & Lama pemanfaatan jenis kayu Irian & 14 & 3 & - & 17 \\
2. & Alasan pemanfaatan & 17 & - & - & 17 \\
3. & Bagian tumbuhan yang dimanfaatkan & 2 & 5 & 10 & 17 \\
4. & Pengetahuan tentang pemanfaatan jenis & 15 & - & 2 & 17 \\
5. & Kelebihan pala Irian dengan yang lain & 14 & 4 & 1 & 17 \\
\hline
\end{tabular}

Ket: A, B dan C merupakan variasi jawaban quisioner dari setiap responden

Sumber : Data Primer Tahun 2014

Berdasarkan Tabel 4 diatas dapat lihat bahwa hampir sebagian besar masyarakat memanfaatkan kayu Pala Irian (Myristica argentea Warb.), hal ini disebabkan karena kebutuhan mereka yang harus dipenuhi seperti kabutuhan akan kayu bakar (kayu energi), bahan konstruksi bangunan dan lain-lain. Tabel 4 juga menunjukan bahwa seluruh masyarakat yaitu sebanyak (17 KK) memanfaatkan kayu Pala Irian (Myristica argentea Warb.) yang berada di areal hutan sekitar Kampung Haha.

Berdasarkan pengamatan dan wawancara di lapangan diketahui bahwa sebagian masyarakat yaitu sebanyak 9 KK memanfaatkan semua jenis kayu yang ada di areal hutan Kampung Haha, sedangkan sebagian masyarakat yang lain yaitu sebanyak $8 \mathrm{KK}$ memanfaatkan kurang dari 5 jenis. Hal ini dikarenakan mereka memanfaatkan sesuai dengan kebutuhan mereka. Dari tabel 4 diatas dapat dilihat bahwa jumlah masyarakat yaitu sebanyak $10 \mathrm{KK}$ memanfaatkan semua bagian dari kayu Pala Irian (ranting, cabang, batang dan buah), sementara itu yang memanfaatkan hanya beberapa bagian saja berjumlah $5 \mathrm{KK}$, sedangkan yang sisanya ( $2 \mathrm{KK})$ hanya memanfaatkan sebagian saja.

Menurut tabel 4 diketahui bahwa semua responden masyarakat Kampung Haha yaitu sebanyak 17 KK mendapatkan pengetahuan tentang pemanfaatan kayu Pala Irian secara turun-temurun. Hasil pengamatan di lapangan diketahui bahwa seluruh masyarakat responden mengatakan bahwa kayu pala Irian sangat baik karena dapat dimanfaatkan sebagai kayu bakar, bahan konstruksi bangunan, dan juga tahan terhadap genangan air laut. 
9. Konservasi dan Kelembagaan Pengelolaan Jenis Kayu Pala Irian (Myristica argentea Warb.)

Berdasarkan hasil pengamatan dan wawancara masyarakat responden dilapangan tentang upaya konservasi dan kelembagaan yang dilakukan oleh masyarakat Kampung Haha dapat dilihat pada tabel berikut ini:

Tabel 5. Distribusi jawaban masyarakat responden tentang upaya konservasi dan kelembagaan terhadap jenis kayu Pala Irian di Kampung Haha Distrik Seremuk Kabuapeten Sorong Selatan

\begin{tabular}{llcccc}
\hline \multirow{2}{*}{ No. } & \multicolumn{1}{c}{ Uraian } & \multicolumn{3}{c}{ Jumlah Masyarakat } & \multirow{2}{*}{$\Sigma$} \\
\cline { 3 - 5 } & & $\mathrm{A}$ & $\mathrm{B}$ & $\mathrm{C}$ & \\
\hline 1. & Pemahaman tentang kayu Pala Irian & 17 & - & - & 17 \\
2. & Tindakan konservasi dan kelembagaan & 3 & 9 & 5 & 17 \\
3. & Populasi jenis kayu pala Irian & - & 17 & - & 17 \\
4. & Keterlibatan institusi lokal & - & - & 17 & 17 \\
\hline
\end{tabular}

Keterangan: $\mathrm{A}, \mathrm{B}$ dan $\mathrm{C}$ merupakan variasi jawaban quisioner dari setiap responden

Sumber : Data Primer Tahun 2014

Berdasarkan tabel diatas terlihat bahwa hampir semua masyarakat responden mengetahui akan kayu Pala Irian, hal ini karena merupakan usaha turun temurun dari masyarakat tersebut. Tabel diatas juga terlihat bahwa sebagian besar msyarakat responden (9 KK) mengatakan bahwa tindakan konservasi sudah dilakukan namun hanya dalam kategori penanaman dan pemeliharaan saja. Selain itu, seluruh masyarakat (17 KK) mengatakan bahwa populasi kayu Pala Irian (Myristica argentea Warb.)sudah jarang, hal ini akibat dari laju eksploitasi melebihi daya tumbuhnya. Hal lain juga bahwa sejak beroperasinya HPH PT. Hasrat Wira Mandiri, banyak juga jenis kayu ini dieksploitasi secara besar-besaran. Sedangkan terkait dengan keterlibatan institusi lokal dalam upaya pengelolaan kayu Pala Irian (Myristica argentea Warb.) ini masih terlihat kurang sama sekali. Kondisi ini disebabkan karena kurangnya penelitian dan publikasi akan spesies kayu ini.

\section{P E N U T U P}

\section{A. Kesimpulan}

Dengan melihat sedemikian intens dari hasil penelitian dan uraian pembahasan dari skripsi ini, maka secara refresentatif dapat ditarik beberapa kesimpulan sebagai berikut :

1. Ciri dan karakteristik kayu Pala Irian (Myristica argentea Warb.) sama dengan bebera spesies pala rempah-rempah, hal ini dapat dilihat dari seluruh organ tanaman. CM dan karakteristik kayu Pala Irian (Myristica argentea Warb.)sama dengan beberapa spesies kayu pala lainnya di Indonesia diantaranya sebagai berikut: pohon berbatang tunggal, tumbuh dengan tinggi mencapai $25 \mathrm{~m}$, tumbuh pada tanah basah sampai kering dan berasosiasi dengan tumbuhan apa saja. Bentuk pohon pala berpenampilan indah menjulang tinggi ke atas dan kepinggir, lonjong (silindris) dan bulat dengan percabangan relatif teratur, Daunnya berwarna hijau dengan bintik-bintik kuning, panjang -10-15 $\mathrm{cm}$ dengan lebar 5$10 \mathrm{~cm}$, panjang tangkai daun dapat mencapai $5 \mathrm{~cm}$; bunganya keluar dari ujung cabang dan ranting, bentuk buah bulatmemanjang, ukuran diameter buah dapat mencapai $5 \mathrm{~cm}$ dengan permukaan kasar. + Buahnya bulat sampai lonjong, berwarna hijau kekuning- 
kuningan, apabila masak akan berbelah dua, diameter 3-6 cm.

2. Pemanfaatan kayu Pala Irian (Myristica argentea Warb.) oleh masyarakat di Kampung Haha Distrik Seremuk Kabupaten Sorong Selatan sebagaian besar dipergunakan untuk perkakas rumah tangga, kayu bakar (kayu energi), pembuatan perahu (kano) dan berbagai souvenir lainnya.

3. Pemanfaatan pohon kayu Pala Irian (Myristica argentea Warb.) oleh masyarakat Kampung Haha Distrik Seremuk hanya dominan adalah kayunya saja, dimana harga jual kayu tersebut dapat mencapai Rp. $750.000,-$; selain itu daging buah Pala Irian sangat baik dan sangat digemari oleh masyarakat jika telah diproses menjadi makanan ringan, misalnya: asinan pala atau manisan pala.

4. Prospek pemanfaatan Pala Irian (Myristica argentea Warb.) kayunya cukup prospektif dan memberikan kontribusi pendapatan yang cukup baik sebagai sumber penghasilan masyarakat setempat.

5. Persepsi pengetahuan masyarakat akan manfaat kayu Pala Irian (Myristica argentea Warb.) oleh masyarakat setempat diperoleh secara turun-temurun dan selama ini belum ada upaya konservasi dari institusi lokal dan luar untuk melindungi spesies pala Irian ini.

\section{B. $S$ a $\mathbf{r}$ a $\mathbf{n}$}

Refresentasi dari hasil penelitian, uraian dan kesimpulan skripsi ini serta sekaligus sebagai usaha memperkenalkan khasanah kayu Pala Irian (Myristica argentea Warb), sekaligus memberdayakan masyarakat akan tumbuhan tersebut yang ada didalam Kampung Haha Distrik Seremuk Kabupaten Sorong Selatan, untuk itu dapat disarankan :
1. Kawasan hutan Kampung Haha Distrik Seremuk cukup kaya akan potensi kayu Pala Irian (Myristica argentea Warb), dan sebagian diantaranya telah banyak dimanfaatkan oleh masyarakat setempat sebagai sumber pendapatan, sehingga perlu dilakukan upaya pelestarian dan peremajaan tumbuhan tersebut yang merupakan sumber daya alam yang bermanfaat bagi masyarakat setempat.

2. Perlu dilakukan penelitian lanjutan yang lebih diarahkan pada analisis ekonomi pemanfaatan kayu dan buah Pala Irian (Myristica argentea Warb), yang ada di Kampung Haha Distrik Seremuk.

\section{DAFTAR PUSTAKA}

Anonim, 2009. Laporan Tahunan Badan Meteorodologi dan Geofisika Kabupaten Sorong Selatan.

Arrijani., 2005. Biologi dan Konservasi Marga Myristica di Indonesia. Jurnal Biodiversitas Vol. 6 N0.2. ISSN: 1412-033X

Deynum dkk., 1949. Sejarah dan Penyebaran Tanaman Pala Botani Pemasaran. Aneka Ilmu jalan raya semarang Km 8,5.

Hatta. S., 1993, Budidaya Pala Komonitas Ekspor, Kanisius Yogyakarta

Hadad. E. A dan Auzay Hamid dkk 1989. Mengenal Berbagai Plasma Mutfah. Badan Litbang pertanian Maluku Utara.

Hadad, E. A., O. Rostiana, C. Firman, T. Sugandi, W. Lukman, A. Wikanda, dab Suparman., 2004. Koleksi, Karakterisasi dan Evaluasi Plasma Nutfah Pala. Laporan Bagian Proyek Pengkajian Teknologi Pertanian Partisipatif. Balittro.

Heyne., 1987. Sejarah Singkat Sentral Penanaman Pala di Maluku Utara. Pedoman Bercocok Tanam 
,Tanaman Pala BIP di Aceh, Departemen Pertanian

Hutapea, J.R. 1994. Inventaris Tanaman Obat Indonesia III. Jakarta: Departemen Kesehatan Republik Indonesia.

Kadri., 1992. Marketing Produk Pertanian dan Industri,Penerbit Renika Cipta Jakarta

Marzuki, I., Ulluputty, M. R., Sandra, A. A. dan Memen, S., 2008. Krakterisasi Morfoekotife dan Proksimat Pala Banda (Myristica fragrans Houtt). Bul. Argon. 36(2): 145-151.

Wahyudi.A.dkk 1995, Analisis Harga Pala Indonesia di Pasar Internasional, Jurnal Penelitian Taman Industri

No.1,Vol.1.Penelitian,
Pengembangan Tanaman Industri (PPTI) Jakarta.

Wahyuni, S., Hadad, E. A., Suparman, dan Mardiana., 2008. Keragaman Produksi Plasma Nutfah Pala (Myristicafragrans) di KP Cirurug. Buletin Plasma Nutfah Vol. 14 No.2 Th.2008.

Wardiana, E., Randriani, e., dan Tresniawati, C., 2007. Seleksi Beberapa Karakter Penting 15 Aksesi Tanaman Pala (Myristica fragrans) di Kebun Percobaan Cirurug Sukabumi. Zuriat.18(2): 169-179.

UUD No 41 Tahun 1990, Tentang Konservasi, Sumber Daya Alam Hayati dan Ekosistem, Jurnal BKSDA Papua II Kabupaten Sorong Selatan. 